* Doutor em Direito do Estado pela Pontifícia Universidade Católica de São Paulo. E-mail: ewp@erickpereira.adv.br

** Mestranda em Direito pela Universidade Federal do Rio Grande do Norte. E-mail: marylia_ferreira@hotmail.com

\section{Breve cotejo entre as teorias dos sistemas e do discurso e a "sombra" da crise do Estado Democrático de Direito}

\author{
BRIEF COLLATION BETWEEN AS SYSTEMS AND \\ THEORIES OF SPEECH AND THE "SHADOW" THE \\ Crisis of Democratic State Law
}

\author{
Erick Wilson Pereira * \\ Marília Ferreira Silva **
}

Resumo: O presente estudo destina-se a esclarecer aspectos obscuros da realidade brasileira que degradam o ambiente constitucional, maquiados pelo pálio do "Welfare-State", estimulados, em grande parte, pelo descompasso entre a multiplicação das demandas sociais e o ritmo desacelerado na eficiência das estruturas normativas, dentro da perspectiva da crise constitucional que assalta o Estado Democrático de Direito. Para tal desiderato, tratar-se-á da crise desse modelo de Estado e do forte impacto sofrido pelo Direito, após compreendê-lo à luz das Teorias Sistêmica e Discursiva.

Palavras-chave: Estado Democrático de Direito. Sistemas. Crise Constitucional.

Abstract: This study is intended to clarify obscure aspects of the Brazilian reality that degrade the constitutional environment, masked by the cloak of "Welfare-State", stimulated, in large part, by the mismatch between the multiplication of social demands and the slowed pace at the efficiency of the normative structures, within the perspective of the constitutional crisis that assails the Democratic State of Law. For this aim, it will be treated the crisis of this model of State and the strong impact suffered by the Law, after comprehending it at the light of the Systemic and Discursive Theory.

Keywords: Democratic State of Law, Systems, Constitutional Crisis. 


\section{A ORIGEM DOS SISTEMAS E A MODERNIZAÇÃO SOCIAL}

É interessante, inicialmente, voltar-se, brevemente, aos modelos de evolução social propostos por Luhmann e Habermas, para melhor compreensão do atual estágio do Estado Democrático de Direito, passando pelo processo de complexificação da sociedade.

Conforme o modelo sistêmico luhmanniano (LUHMANN, 1997, p. 413), a evolução se manifesta com a transformação do improvável em provável, implicando, assim, "o paradoxo da probabilidade do improvável" (LUHMANN, 1997, p. 454). Ocorre evolução, então, quando aquilo que é desviante passa a integrar a estrutura do respectivo sistema. Para tanto, a evolução está condicionada por três elementos: variação, seleção e restabilização ou retenção (mecanismos evolutivos ou funções da evolução que só têm relevância evolutiva em conjunto).

"A variação consiste em uma reprodução desviante dos elementos através dos elementos do sistema" (LUHMANN, 1997, p. 454), realizando-se quando a comunicação desvia-se do modelo estrutural de reprodução social, trata-se de uma comunicação inesperada, surpreendente. A seleção ocorre, por conseguinte, para possibilitar a continuidade da reprodução do elemento inovador. Porém, apesar dessa assimilação estrutural da inovação ser imprescindível à ocorrência do acontecimento evolutivo, ela lhe é insuficiente.

Logo, para que se complete o processo evolutivo singular

impõe-se a restabilização como mecanismo que, no plano da formação do sistema como unidade de reprodução, vem assegurar à estrutura inovadora 'duração e capacidade de resistência (NEVES, 2008, p. 2),

o que só será possível se as estruturas inovadoras forem incorporadas como parte de uma unidade reprodutiva auto-referencial de comunicações, seja esta a sociedade como um todo ou seus sistemas parciais. Pode-se afirmar, então, que a restabilização diz respeito à compatibilização das novas expectativas com o sistema.

Evolução se apresenta, pois, como um conceito-gênero que se submete a especificações analíticas, conforme se refira aos sistemas biológicos, psíquicos ou sociais.

Contudo, sem o intuito de furtar do modelo darwiniano a sua importância para a compreensão dos mecanismos evolutivos, afasta-se aqui o dogmatismo 
da seleção natural. Isso porque a teoria sistêmica enfatiza que a evolução resulta de transformações internas na respectiva unidade de reprodução, de modo que "as perturbações advindas do ambiente só se tornam determinantes da evolução sistêmica quando assimiladas internamente como inovações”, após o processo da restabilização.

Desse modo, a conduta desviante é avaliada como algo interno à sociedade, a ser tratado por procedimentos de aplicação jurídica fundados em representações morais válidas para todas as esferas sociais.

Os próprios procedimentos de solução de conflitos destinam-se basicamente a averiguar a adequação das condutas ao modelo estrutural de expectativas evidentes e inquestionáveis (NEVES, 2008, p.9),

significando isso a presença de um plexo de valores, imediatamente válido como padrão comportamental em todas as esferas da vida em sociedade, o que legitima a dominação da camada superior, onde atua a moral conteudística como freio aos desvios inovadores.

Na perspectiva da teoria da evolução, destaca-se que os sistemas funcionais são estabilizados no sentido da variação, de tal sorte que o mecanismo da estabilização atua simultaneamente como motor da variação evolutiva (LUHMANN, 1997, p. 494).

Disso decorre que a sociedade torna-se excessivamente complexa e dinâmica.

Assim, chega-se à questão da modernidade. Durkheim, em sua perspectiva evolucionária, fala de uma preponderância progressiva da solidariedade orgânica (DURKHEIM, 1986, p.119), tendo em primeiro lugar um significado moral. Na concepção weberiana da modernidade, acentua-se o processo de racionalização social, o que implica a pontuação do racionalismo com respeito aos fins das condutas, institucionalizado através da racionalização legal da dominação, em detrimento dos fundamentos tradicionais com respeito a valores.

De outro modo, para explicar, mais abrangentemente, a emergência da sociedade moderna, Luhmann utiliza o critério da complexidade, "entendida como presença permanente de mais possibilidades (alternativas) do que as que são suscetíveis de ser realizadas" (NEVES, 2008, p. 15), não se negando a possibilidade de construções altamente complexas serem destruídas ou mesmo 
substituídas por "simplificações superiores" no processo evolutivo, definindo "a crescente complexidade da sociedade" como "motor da evolução" (LUHMANN, 1997, p. 106). Isso implica, portanto, o desaparecimento de uma moral tradicional, válida para todas as esferas de convivência, e o surgimento de sistemas sociais operacionalmente autônomos (autopoiéticos), reproduzidos com base nos seus próprios códigos e critérios, embora condicionados e influenciados pelos seus respectivos ambientes.

Por um lado, a supercomplexidade envolve supercontigência e abertura para o futuro; por outro, provoca pressão seletiva e diferenciação sistêmicofuncional. Não se questiona aqui que uma sociedade é moderna na medida em que alcança um alto grau de complexidade, contingência e abertura para o futuro, pois que é muito frequente a insuficiência da realização destes.

No que concerne ao modelo habermasiano ${ }^{1}$ da evolução social, desenvolvidos nos limites da Teoria do Discurso, também se reconhece o aumento da complexidade sistêmica como aspecto relevante do processo evolutivo social. Entretanto, diferenciando-se do modelo luhmanniano, enfatiza a "lógica do desenvolvimento", considerando, decisivamente, os estágios da consciência moral, o que põe o processo de evolução a depender do desenvolvimento de mecanismos de aprendizado, de modo que os processos de diferenciação tanto podem ser indícios de evolução quanto causas de estagnação evolutiva (NEVES, 2008, p.25).

É, sobretudo, a analogia entre "imagens do mundo e o sistema de delimitações do eu" que se apresenta relevante para Habermas (2003, p.18). Nesta senda, a sociedade moderna encontra-se no estágio pós-convencional de desenvolvimento da consciência moral, diferentemente das sociedades arcaicas, relacionada com um modelo de moral pré-convencional, e das chamadas "culturas avançadas" (estágio convencional), correspondente a um nível convencional de desenvolvimento moral.

Não só a ciência, mas também a Arte, a Moral e o Direito desprendemse com o desenvolvimento da sociedade moderna, do âmbito sacro. Essa dessacralização possibilita a emergência de discursos críticos contra as próprias instituições existentes. Habermas oferece um diagnóstico da modernidade

\footnotetext{
${ }^{1}$ Para Habermas, a modernidade resulta da evolução da consciência moral no sentido da superação das estruturas pré-convencionais e convencionais e o advento de uma moral pós-convencional. Isso significa uma clara diferenciação entre sistema e "mundo da vida", aquele como espaço de intermediação do "agir-racional-com-respeito-a-fins" (instrumental e estratégico), este enquanto horizonte do "agir comunicativo", orientado na busca do entendimento intersubjetivo. Nessa perspectiva, a modernidade exige positivamente a construção de uma "esfera pública".
} 
contrário tanto aos modelos fragmentários quanto aos paradigmas de crítica à ideologia, vez que relaciona reflexivamente ao agir comunicativo (orientado para o entendimento) uma racionalidade discursiva, não subordinada a determinações sistêmicas; e, por fỉm, contra a tendência dominante, enfatiza a presença de uma moral pós-convencional e universalista como característica dominante da sociedade moderna.

Consoante a abordagem habermasiana, a modernidade é concebida pelo marxismo, especialmente, como diferenciação da Economia e do Estado, em termos de uma "racionalidade-com-respeito-a-fins" (NEVES, 2008, p.15) e de neutralização moral dessas esferas, sendo esta neutralização também aceita por Luhmann, ou seja, a modernidade é compreendida como diferenciação racional-finalística dos sistemas econômico, político e jurídico, implicando a neutralização moral dessas esferas.

Por consequência, o surgimento e o desenvolvimento da sociedade moderna pressupõem a evolução das estruturas da consciência no sentido de uma noção pós-convencional e universalista de Moral e Direito, isto é, dependem de uma "lógica de desenvolvimento" autônoma.

Habermas, então, relativiza a crítica da "razão instrumental", atribuindo o problema da modernidade não mais ao desenvolvimento técnico em si mesmo, mas sim à hipertrofia da "racionalidade-com-respeito-a-fins", através de uma noção de esfera social não subordinada a imperativos sistêmicos que o afasta da Teoria dos Sistemas.

Este teórico alemão, diante dessas noções, sintetiza a sua concepção da modernidade da seguinte forma:

a) A emergência da sociedade moderna relaciona-se primacialmente com o desenvolvimento das estruturas da consciência;

b) Portanto, a modernidade não se restringe ao domínio da 'razão instrumental', caracterizando-se, antes, pela relevância da 'razão prática';

c) A modernização implica a diferenciação progressiva entre sistema e mundo da vida, o que se relaciona com o fato de que a complexidade daquele e a racionalidade deste aumentam simultânea e complementarmente;

d) Nesse sentido, o agir comunicativo, orientado para o entendimento, diferencia-se do agir racional-com-respeito-a-fins (instrumental ou estratégico), orientado para o êxito;

e) A compreensão do mundo torna-se descentrada (mundo objetivo, social e subjetivo) tanto no plano da ação quanto no nível do discurso;

f) Com a diferenciação entre a ação e discurso, as diversas pretensões de 
validade (verdade, retidão e sinceridade) passam a ser suscetíveis de questionamento reflexivo em diversas formas de discurso;

g) O universalismo moral e jurídico viabiliza a integração social em um contexto de pluralismo em torno de valores e interesses, possibilitando a construção do consenso. (NEVES, 2008, p. 53).

\section{A CONSEQUENTE "MODERNIZAÇÃO DO DIREITO"}

Diante do já delineado, mister transcorrer algumas linhas que versem sobre a evolução do Direito, corolário imediato da evolução social acima analisada.

A sociedade em seu processo evolutivo passou por estágios de desenvolvimento de uma moral conteudística, a saber, o pré-convencional, o convencional e o pós-convencional, os quais correspondem, respectivamente, aos estágios evolutivos do Direito: o revelado, o tradicional e o estatuído, formal ou positivo. Ainda se pode acrescentar um outro nível, o Direito deduzido, que precede à positivação, espécie de primeiro estágio do modelo pósconvencional.

O Direito revelado, correspondente ao nível pré-convencional da consciência moral, baseia-se numa ética mágica, "apoia-se fundamentalmente em expectativas de comportamentos particulares" (NEVES, 2008, p. 54), não existindo a noção de norma como expectativa generalizada de comportamento. Os conflitos são solucionados concretamente, mediante autocomposição, autodefesa e retaliação, sem interferência de terceiros. Não se consideram, pois, as intenções do agente, mas sim seus resultados, importando o dano objetivo e, sobretudo, o restabelecimento do status quo ante.

Pode-se dizer que, nessa orientação, o Direito ainda não é coercitivo.

Só com o Direito tradicional das denominadas "culturas avançadas", correspondente ao nível moral convencional e a uma ética da lei, a norma como expectativa generalizada de comportamento torna-se a categoria fundamental de orientação da conduta ${ }^{2}$, passando, pois, a distinguir o plano da

\footnotetext{
${ }^{2}$ Uma nova concepção do papel do direito na sociedade tem com ponto de partida a idéia de que o direito reflete um modo peculiar do agir social. Portanto, o direito não é só ordem, ele também se constrói 'no' e vive 'do' conflito: aqui inclui-se a possibilidade do direito também engendrar desordem e conflito. Por isso, Luhmann aponta o direito como um dos principais fatores de integração social, mas também aponta seu papel desintegrador. Como um sistema social, o direito é também um sistema autopoiético que reproduz suas próprias operações recorrendo a essas mesmas operações: ou seja, ele é um sistema operacionalmente fechado e determinado pela estrutura, diferenciando-se, por isso, do seu ambiente.
} 
ação e o normativo, em razão da centralização do poder nas sociedades estatalmente organizadas.

Habermas entende que a autoridade política se baseia no fato de dispor de meios de sanção centralizados, o que confere às decisões do detentor do cargo caráter vinculante, assim é que as violações à ordem normativa já são avaliadas de acordo com a intenção de um sujeito responsável, não apenas a partir de seus resultados. Não se trata mais de compensar os danos causados, mas sim de reparar os ilícitos cometidos e "curar o ferimento de normas" (HABERMAS, 2003, p. 264).

Contudo, Direito, Moral e Ética, ainda aqui, constituem um amálgama sacramente fusionado, de modo que o ordenamento normativo a aplicar nos procedimentos jurisdicionais ainda não se encontra diferenciado juridicamente.

É essa fusão, essa indiferenciação entre Poder e Ordem jurídicomoral sacramente fundamentada que impede, conforme o modelo habermasiano, a reflexão crítica das normas vigentes a partir de princípios, uma vez que as instituições convencionais são incontestáveis. O contrário representaria perigo à manutenção da ordem dominante, um desvio juridicamente condenável.

$\mathrm{O}$ dito Direito deduzido traz em seu cerne, mesmo que timidamente, a presença de uma base principiológica da qual se pode extrair os fundamentos de avaliação das instituições jurídicas tradicionais. É uma fase de transição do período do jusnaturalismo para a plena positivação do Direito, na qual ainda se fusionam as esferas do ético, do moral e do jurídico, sendo a validade do Direito deduzida de postulados metafísicos e, embora criticáveis, permanecem inquestionáveis.

Com a positivação do Direito na sociedade moderna, cinge-se a antiga fusão, diferenciando-se plenamente moralidade, eticidade e juridicidade. Os princípios especificamente jurídicos passam a ocupar o lugar dos princípios de natureza metajurídica para fundamentar as normas jurídicas.

O Direito positivo, que corresponde ao nível da moral pós-convencional, apesar de diferenciado da moral e da ética, é indissociável da fundamentação. Além da positividade, do legalismo e da formalidade como três características do Direito moderno, Habermas aponta-lhe a generalidade ou universalidade. Eis a questão! Ao perder os seus fundamentos sacros, o Direito, por um lado, assume o papel de instrumento do poder e do mercado, mas, por outro, exige uma fundamentação em termos de uma racionalidade procedimental tanto ética quanto moral. 
A legitimação procedimental implica, então, a criticabilidade dos princípios jurídicos à luz de uma racionalidade abrangente, envolvendo questões jurídicas (de consistência), pragmáticas (de estabelecimento de fins e determinação dos meios adequados a alcançá-los), ético-políticas (de valores) e morais (de justiça), assim como questões concernentes ao compromisso equitativo. (NEVES, 2008, p. 58).

Acerca da contraposição ao amoralismo do sistema luhmanniano à fundamentação ética de Habermas, ambas as concepções da modernidade aproximam-se, na medida em que se referem à superação da moral tradicional conteudística e hierárquica. Pode-se afirmar que Luhmann procura enfatizar empiricamente o dissenso em torno de conteúdos morais na modernidade. Habermas discute a construção do consenso mediante procedimentos com potencialidade normativa universal como característica da modernidade, sem desconhecer a diversidade de conteúdos valorativos.

\section{A CONCEPÇÃO DE ESTADO DEMOCRÁTICO DE DIREITO DENTRO DAS TEORIAS DOS SISTEMAS E DO DISCURSO}

A diferenciação do Direito na sociedade moderna pode ser interpretada como controle do código-diferença "lícito/ilícito", oriundo de sua positivação, implicando o controle exclusivamente pelo sistema jurídico, que adquire assim seu fechamento operativo. Na medida em que o princípio de diferenciação baseava-se em uma distinção entre "superior/inferior", o Direito permanecia sobredeterminado pela Política e pelas representações morais estáticas, político-legitimadoras, não dispondo exclusivamente de um código diferença específico entre um sim e um não.

O Direito constitui, pois, em outras palavras, "um sistema normativamente fechado, mas cognitivamente aberto" (NEVES, 2008, p. 81), e em razão disso se pode dizer que sua qualidade normativa serve à autopoiese do sistema ${ }^{3}$ e sua qualidade cognitiva serve à concordância desse processo com o ambiente do sistema.

Com base nisso, a capacidade de aprendizagem (dimensão cognitivamente aberta) do Direito positivo possibilita que ele se altere para se adaptar ao ambiente complexo e veloz. O fechamento normativo, por

\footnotetext{
${ }^{3}$ Constituição como o complexo normativo que "representa o escalão de direito positivo mais elevado da ordem jurídica estatal” (KELSEN, 1960, p. 228-230).
} 
sua vez, impede a confusão entre sistema jurídico e seu ambiente, permitindo que a alterabilidade do Direito ocorra conforme critérios internos e específicos de um sistema capaz de aprender e se reciclar, sensível ao seu ambiente. Isto porque o fechamento auto-referencial, a normatividade do sistema jurídico, não é por si só finalidade do sistema, mas, antes, é a condição à sua abertura. $\mathrm{O}$ fechamento cognitivo, pois, proporcionaria um paradoxo insuperável da autopoiese e, de outro modo, o fechamento normativo, mediante o questionamento do código-diferença "lícito/ilícito" afetaria a autonomia do sistema jurídico. A diferenciação do Direito na sociedade não é outra coisa senão o resultado da mediação dessas duas orientações.

Pressuposto que à positivação do Direito é inerente não apenas a supressão da determinação imediata dele pelos interesses, vontades e critérios políticos dos "donos do poder", mas também a neutralização moral do sistema jurídico, torna-se irrelevante para Luhmann uma teoria da justiça como critério exterior ou superior ao Direito positivo. Em suma, nos termos da concepção luhmanniana da positividade do Direito, isto é, fechamento normativo e abertura cognitiva do Direito moderno, o problema da justiça é reorientado para a questão da complexidade adequada do sistema jurídico e da consistência de suas decisões.

No modelo sistêmico, o Estado Democrático de Direito apresentase, em princípio, como autonomia operacional do Direito, isto é, o sistema jurídico reproduz-se primariamente a partir de um código binário de preferência próprio (lícito/ilícito) e de seus próprios programas (Constituição, leis, decretos, jurisprudências, negócios jurídicos, atos administrativos, etc.). Ocorre que isso não é suficiente para configurar o Estado de Direito, pois que este pressupõe a diferenciação entre os sistemas jurídico e político. Neste parâmetro, o Estado de Direito pode ser definido, em princípio, como relevância da distinção entre lícito e ilícito para o sistema político. Isso significa que "todas as decisões do sistema político estão subordinadas ao direito" (LUHMANN, 1996, p. 199), resultando uma interdependência entre esses dois sistemas. Da presença do segundo não decorre a superposição das preferências "poder" e "lícito" ou "não-poder" e "ilícito", mas sim que as disjunções poder/não-poder e lícito/ilícito refiram-se reciprocamente. Trata-se de uma simbiose: de um lado as decisões políticas subordinam-se ao controle jurídico e de outro o direito positivo não pode prescindir, por exemplo, de legislação controlada e deliberada politicamente. 
Nos moldes pré-modernos de dominação, assim como no modelo absolutista e nas autocracias contemporâneas, o que se constata é a subordinação do Direito à Política.

A hierarquia política não permite que se dê ao jurídico a relevância merecida, de tal sorte que o código-preferência "lícito/ilícito" só é real e vinculante para os que estão nas camadas hierarquicamente inferiores da relação de poder. À guisa de exemplo, no período absolutista dava-se relevância especial o princípio "Princeps legibus solutus est” (“O príncipe está isento da lei”), pelo qual o detentor do poder não está subordinado a este sistema de diferenciação e suas decisões não são avaliadas conforme o código jurídico, mas antes pressupostas lícitas. Assim, demonstra-se que tal diferenciação hierárquica subjuga o Direito em detrimento da Política e é por demais antiga.

Com a inserção do código preferência "lícito/ilícito" como segundo código do Poder, no Estado de Direito, chega-se a uma relação sinalagmática entre sistemas político e jurídico. Desta forma, por um lado, o ordenamento jurídico constitucional confere competências, direitos e prerrogativas ao Estado ou governantes, mas também lhes impõe deveres e responsabilidades perante os cidadãos, grupos sociais e organizações privadas. Por outro lado, inobstante tal prescrição, a ordem jurídica também prescreve aos indivíduos e organizações, direitos e garantias fundamentais de natureza individual e coletiva. Disso se pode concluir que o Direito não é simplesmente um mecanismo justificador do poder ou um instrumento de dominação, mas também serve à delimitação e ao controle desse mesmo poder. Não significa, portanto, limitação recíproca estática das possibilidades, mas incremento de possibilidades por controles recíprocos.

Ao contrário do modelo hierárquico unilateral que encerra imobilidade e inflexibilidade:

Esquema 1 - Modelo hierárquico unilateral

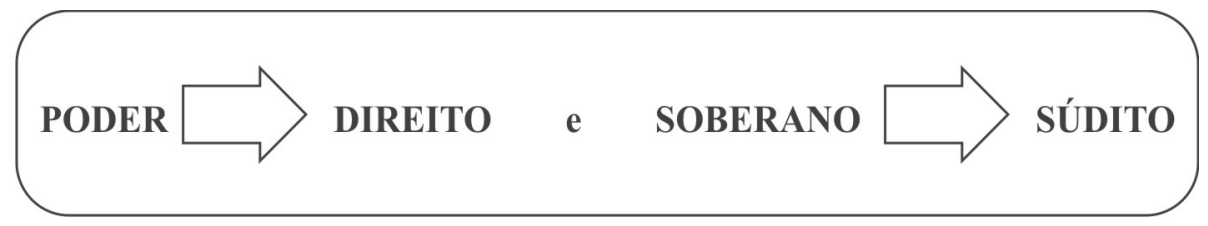

o esquema circular que importa ampliação das possibilidades através de controles e limitações mútuas: 
Esta circularidade, resulta da reciprocidade entre os dois sistemas: se o Direito normatiza procedimentos eleitorais e parlamentares, entre outros; a Política decide pela incorporação de novas estruturas normativas no sistema jurídico. Porém, a circularidade típica do Estado de Direito significa, sobretudo, uma acentuada interpenetração entre os sistemas jurídico e político, como já reiteradamente ventilado.

\subsection{A proposta de Luhmann}

A diferenciação entre sistemas jurídico e político, no Estado de Direito, realiza-se mediante a Constituição. Na acepção que aqui se põe, não se trata do conceito normativo-jurídico ${ }^{4}$, fáctico-social ${ }^{5}$ ou culturalista ${ }^{6}$, no sentido de que todo e qualquer Estado, pré-moderno ou contemporâneo, absolutista, totalitário ou democrático-liberal, tem uma Constituição. Assim como também não é concebida como ordem total da comunidade no sentido do conceito clássico de politéia. Aqui também se rejeita qualquer conceito decisionista ${ }^{7}$, que implique uma relação hierárquica de sobreposição do Poder ao Direito, conforme o modelo de Schmitt.

Como na concepção luhmanniana, a Constituição é compreendida, especificamente, como fruto da evolução da sociedade moderna, fugindo do paradigma semântico emergente da transição para a época moderna, no âmbito do qual a Constituição era conceituada como carta de liberdade ou

\footnotetext{
${ }^{4}$ Constituição como "as relações de poder realmente existentes em um país" (LASSALE, 1987, p. 130).

${ }^{5}$ Constituição como dialética de normalidade (real) e normatividade (ideal) (HELLER, 1934, p. 249) ou como norma e realidade do Estado como processo de integração (SMEND, 1968, p. 136 e 189 91).

${ }^{6}$ Constituição como "decisão de conjunto sobre modo e forma da unidade política" (SCHMITT, 1970, p. 20).

${ }^{7}$ Em Luhmann, o conceito de "acoplamento estrutural" ocupa um lugar central na teoria biológica dos sistemas autopoiéticos de Maturana e Varela, 1980, à qual Luhmann explicitamente recorre na aplicação dele aos sistemas sociais. Trata-se, pois, da teoria dos sistemas autopoiéticos.
} 
pacto de poder. Contexto onde surge, nos quadros das revoluções burguesas do século XVIII, o constitucionalismo moderno, "cuja semântica aponta tanto para o sentido normativo quanto para a função 'constituinte de poder', 'abrangente' e 'universal' da Constituição".

Esta acepção de Constituição é oferecida pela Declaração dos Direitos do Homem e do Cidadão de 1789 e é tida como estritamente moderna, sendo possível inferir que é fator e produto da diferenciação funcional entre Política e Direito como subsistemas da sociedade. Pode ser encarada como um meio jurídico de limitação ao poder do governo, ao contrário do regime arbitrário, mas não resulta necessariamente um "conceito ideal", pelo que não é concebida, forçosamente, com uma declaração de valores ou princípios político-jurídicos fundamentais inerentes à pessoa humana ou conquistados historicamente.

É diante desses pressupostos que Luhmann define Constituição como “acoplamento estrutural" entre Política e Direito ${ }^{8}$. Nessa perspectiva, a Constituição transcende a simples viabilização de prestações recíprocas, funcionando como mecanismo de interpenetração permanente e concentrada entre dois sistemas sociais autônomos, a Política e o Direito, assumindo tal forma, na medida em que possibilita influências recíprocas permanentes entre esses dois sistemas, filtrando-as.

Por essa definição, as ingerências da Política no Direito não mediatizadas por mecanismos especificamente jurídicos, são excluídas, e vice-versa. Este é um vínculo intersistêmico horizontal, típico de um Estado de Direito, onde a autonomia operacional de ambos os sistemas é condição e resultado da própria existência do acoplamento.

Isto porque o efeito destrutivo da Política sobre o Direito afeta não apenas a racionalidade jurídica, mas também produz consequências autodestrutivas, à medida que a diferença "lícito/ilícito" não funciona como código de poder, a Política passa a ser bloqueada por interesses particulares, firmando-se a opressão do Direito pelo poder político ilimitado jurídicoconstitucionalmente.

Luhmann (apud NEVES, 2009) observa, ainda, que

\footnotetext{
${ }^{8}$ Não se trata aqui de uma concepção do Leviatã fixada estritamente na hermenêutica da obra de Hobbes, mas sim da noção do Leviatã disseminada amplamente tanto na Política e no Direito como nas ciências humanas e na filosofia (uma metáfora referente ao poder estatal, não necessariamente ao "Estado do Poder"), noção que se desvincula, em certa medida, de Hobbes e se desenvolve relativamente independente de sua obra.
} 
a Constituição é a forma com a qual o sistema jurídico reage à própria autonomia. A Constituição deve, com outras palavras, substituir apoios externos, tais como os que foram postulados pelo direito natural.

Impede, assim, que critérios externos de naturezas outras como a valorativa, a moral e a política tenham validade imediata no interior do sistema jurídico, delimitando-lhe as fronteiras.

E como bem anota Marcelo Neves, afasta-se, assim, uma hierarquização externa no estilo típico "direito natural '! direito positivo" e constrói-se uma hierarquização interna na ordem jurídica mediante a validade supralegal do Direito Constitucional, do que decorre que qualquer intervenção legiferante do sistema político no Direito é mediatizada por normas jurídicas e o sistema jurídico, por conseguinte, ganha critérios de aplicação do código lícito/ilícito ao procedimento legislativo. Sua normatividade apresenta-se como mecanismo reflexivo do sistema jurídico (norma de normas), fixando os limites da capacidade de aprendizado do Direito.

Ou seja, a Constituição configura-se como o mecanismo mais abrangente de controle da auto-reprodução jurídica e de filtragem das influências do ambiente no direito, enquanto sistema autopoiético. (NEVES, 2008, p. 101).

De outro modo, e antes de tudo, pode a Constituição também ser vista como mecanismo da Política, seja esta instrumental ou simbólica, possibilitando o maior ou menor descompasso entre o sentido político e o jurídico da Constituição. Importa frisar aqui que nos casos de instrumentalismo e simbolismo constitucional não está presente o Estado de Direito, uma vez que tal acepção destrói, corrói, o acoplamento estrutural entre estes dois sistemas, o que implica a própria quebra da autonomia do sistema jurídico, inviabilizando a inserção do código "lícito/ilícito" como segundo código da Política.

A concepção teórico-sistêmica enxerga a institucionalização dos direitos fundamentais como um inibidor social contra uma simplificação totalitária incompatível com o caráter hipercomplexo da modernidade, como um antídoto ao perigo da politização, entendida aqui como sobreposição do código "poder/não-poder" aos demais códigos de preferência ("verdade/ falsidade", "ter/não-ter", “consideração/desprezo", "transcendente/ imanente" e, principalmente, "lícito/ilícito"), isto é, prevalência imediata dos 
critérios políticos em todas as esferas de comunicação: ciência, economia, moral, religião, direito, família, etc.

Aqui é que "essa tendência expansionista e hipertrófica de 'Leviatã'" sofre, com os direitos fundamentais, um freio ativo de "Têmis""10.

\subsection{O modelo de Habermas}

Diferenciando-se radicalmente do modelo analisado até agora, passa-se a breves comentários acerca da concepção de Estado Democrático de Direito na Teoria do Discurso proposta por Habermas.

Nesta teoria, vincula-se o conceito de Estado Democrático de Direito à noção de autonomia do Direito e não à sua positivação como na concepção teórico-sistêmica, sendo que tal autonomia fundamenta-se moralmente, rejeitando a ideia do Direito como um sistema funcional que se auto-regula, impondo, portanto, a necessidade de fundamentação em um procedimento racional. Não significa, pois, confusão entre moral e jurídico. Tampouco significa que o Direito esteja exclusivamente assentado no mundo da vida. "O direito apresenta-se como esfera de intermediação entre sistema e mundo da vida" (NEVES, 2008, p. 107).

A princípio, durante o desenvolvimento do pensamento jurídico habermasiano, concebeu-se o Direito como meio sistêmico e como instituição. Nesse sentido, afirma o próprio Habermas que a distinção anteriormente proposta, que contrapõe as normas jurídicas sociointegrativas às formas jurídicas do controle político, não poderia ser mantida e propõe então um modelo que enfatize o relacionamento íntimo das duas dimensões do fenômeno jurídico no âmbito do Estado Democrático de Direito.

No novo contexto, busca-se apresentar a relação entre instrumentalidade e indisponibilidade do Direito (HABERMAS, 2003, p. 582), de tal sorte que

\footnotetext{
${ }^{9}$ Claro que Têmis, em sua forma feminina (ao contrário da forma masculina de Leviatã), não é o único ícone da justiça na tradição ocidental. Nesse sentido, salientam Curtis e Resnik (1987, p. 1729), citados por Marcelo Neves: "Evidentemente a justiça não é um ícone solitário na tradição ocidental. Antes, é uma de uma série de imagens, a maior parte na forma feminina, associada a conceitos poderosos de virtudes e vícios. Justiça, como muitas dessas imagens, traça sua linhagem a partir de deusas. Seus precursores parecem ter sido Ma'at na cultura egípcia, Themis e Dike na Grécia antiga e, então, Justitia sob o domínio romano".

10 Decorrência direto do fenômeno da globalização, o liberalismo econômico apregoa, preponderantemente, a mínima intervenção do Estado, o afastamento dele, a diminuição do papel do Estado, em prol de uma maior liberdade dos particulares no que tange, essencialmente, às atividades econômicas. Ocorre que a elevação desta realidade a pontos extremos é completamente insustentável no modelo de Estado inaugurado pela Constituição de 1988.
} 
esta conexão tem um significado decisivo no relacionamento do Direito positivo (moderno) com a Moral e a Política:

Aquele momento de indisponibilidade, que também no direito moderno constitui um contrapeso imprescindível para a instrumentalização política do direito como meio, deve-se ao entrelaçamento de política e direito com moral (HABERMAS, 2003, p. 585).

querendo com isso dizer que o Direito, apesar de servir como instrumento de poder, precisa de justificação moral.

A Teoria do Discurso não trata da concepção usual do abismo ou da contradição entre norma e realidade, mas sim de uma tensão inerente ao Direito: a tensão entre facticidade e validade. Aqui não se pode definir a normatividade jurídico-positiva como momento de superação dessa tensão.

A normatividade refere-se à validade e, portanto, exige fundamentação moral ou, mais abrangentemente, justificação discursiva (ou racional) do Direito, fundamentando-se em princípios do estágio da moral pós-convencional, o que diz respeito ao "dever-ser" universalista, incondicionado. Além da fundamentação moral, o modelo habermasiano de Estado Democrático de Direito afirma o caráter legitimador do procedimento democrático:

O Direito não alcança o seu sentido normativo pleno per se, através de sua forma, tampouco mediante um conteúdo moral dado a priori, mas sim através de um procedimento de produção jurídica que gere legitimidade (HABERMAS, 2003, p. 169).

Habermas sustenta uma interligação entre Moral, Política e Direito. Assim sendo, impõe-se, por um lado, uma justificação moral, dando importância à observância e respeito aos princípios de justiça e, por outro, o pluralismo da "esfera pública" exige a consideração da diversidade de valores no âmbito dos procedimentos políticos.

Esquema 2 - Esfera pública

DIREITO

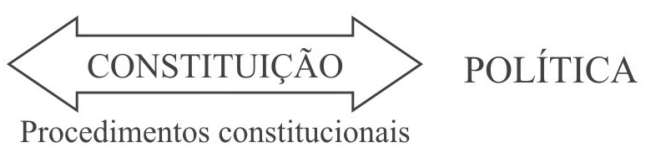

(Procedimento judicial, executivo, legislativo, eleitoral e democrático direito) 


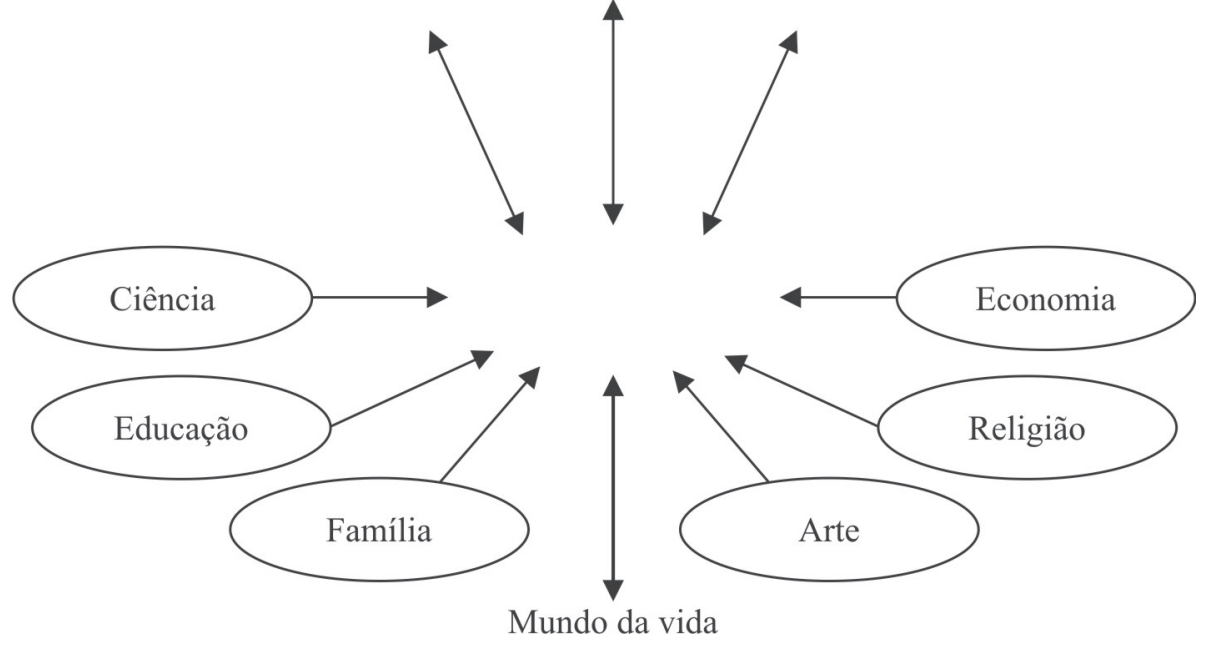

Consoante lição de Marcelo Neves, a esfera pública como arena do dissenso apresenta-se, em princípio, inteiramente desestruturada. Ela só se torna, em certa medida, estruturada quando há perspectivas de que as expectativas, os valores, os interesses e os discursos que lhe são constitutivos sejam generalizados pelos procedimentos constitucionais. E continua acrescentando que estes só podem corresponder adequadamente à heterogeneidade conflituosa da esfera pública na sociedade de hoje se permanecerem abertos, universalista e pluralisticamente, para as diferentes exigências que, com pretensão de generalizar-se política e juridicamente por meio de decisões coletivamente vinculantes e normas jurídicas válidas, afloram na esfera pública. Este é o desafio fundamental do Estado Democrático de Direito em face da esfera pública, isto é, a estruturação dela através da canalização e intermediação procedimental (universalista e pluralista) dos enormes conflitos que a caracterizam, conflitos de expectativas, valores, interesses e discursos.

A concepção habermasiana, pensada fora da atual realidade, vem de encaixe ao presente contexto, haja vista considerar em sua construção que a tensão havida entre facticidade e validade, no Estado Democrático de Direito, estende-se ao âmbito do poder. A compreensão do Direito em face do poder conduz esta teoria à análise de formas discursivas que integram o processo de formação racional da vontade política. 
O discurso pragmático destina-se a justificar os fins e os meios adequados à sua consecução. Nesse caso, as instruções da ação apresentam a forma semântica de imperativos condicionados. O discurso ético-político diz respeito à justificação do modo de vida que é ‘bom' para uma comunidade determinada. Trata-se de estabelecer preferências sobre a 'vida boa'. A questão ético-política refere-se a uma forma particular de vida; os participantes não têm, portanto, pretensão de universalidade, tal como ocorre no discurso moral. O princípio democrático relaciona-se com essas três formas discursivas. Exige fundamentos morais, ético-políticos e pragmáticos. No Estado de Direito, acrescenta-se o discurso jurídico, que se refere ao controle da coerência normativa do sistema jurídico.

Habermas, então, não desconhece o papel do jogo de interesses no processo de formação da vontade estatal. O processo de formação racional da vontade política implica uma conexão complexa entre o discurso pragmático, o ético-político, o moral, o jurídico e as negociações reguladas procedimentalmente (HABERMAS, 2003, p. 207). Esse processo complexo explica "a aceitabilidade racional dos resultados alcançados conforme o procedimento” (HABERMAS, 2003, p. 210).

Apesar desse espectro de compreensão da teoria discursiva, Habermas não se afasta de suas posições originárias: a questão moral (da Justiça), que implica a pretensão de universalidade, tem prevalência sobre as questões jurídicas, ético-políticas e pragmáticas.

\section{A CRISE DO ESTADO DEMOCRÁTICO DE DIREITO}

A concepção moderna do Direito, de cunho predominantemente formal, não preenche mais as expectativas da sociedade, impondo-se pelas novas necessidades da pós-modernidade uma concepção funcional, em que as interpretações jurídicas sejam feitas com o escopo de assegurar eficácia concretiva aos comandos normativos.

Segundo André Ramos Tavares, a força formal da lei foi responsável pela superioridade hierárquica absoluta das leis, num contexto em que não se permitia haver espaço à interpretação do Direito. Veja-se:

A imposição da lei é, assim, tão brutal que não deixa lugar algum para a construção teórica no primeiro positivismo, e menos ainda para a interpretação e criação do Direito fora dos limites da aplicação mecânica da lei. (TAVARES, 2005, p. 37). 
A pós-modernidade representa a destruição dos postulados que delineavam a ordem social, com a instalação do caos ontológico, isto é, a ausência de postulados valorativos para toda a sociedade, aumentando a incredulidade. A ordem que imperava na modernidade é substituída pela ausência de ordem da pós-modernidade, o que implica uma forte tendência para o afloramento de conflitos sociais nessas sociedades, em decorrência da dessubstancialização, da quebra dos paradigmas ontológicos e da fragmentação do seu tecido social provocada pela diversificação econômica, entre outros fatores de relevo. Ou seja, não há parâmetros substantivos que possam, ao mesmo tempo, normatizar as relações sociais e atender às expectativas de toda a variada composição do tecido social, somadas ao enfraquecimento dos órgãos estatais, provocado, essencialmente, pelo liberalismo econômico ${ }^{11}$.

As consequências trazidas pela pós-modernidade atingiram todas as esferas da sociedade, mas o Direito, em especial. Esta ciência que tem o fito de regulamentar as relações sociais sofre de forma mais intensa essas consequências. Isto porque como as relações sociais são cada vez mais complexas, a concepção de Direito formal, baseado na positivação e no formalismo exagerado, entrou em crise, o que afetou, seriamente, a eficácia de suas normas.

O modelo legalista e a lei perdem exclusividade e primeira posição na lista de preferências normativas. Ao lado da hiperlegalidade, havia uma hipolegalidade, pois a lei não mais supria as aspirações sociais. (TAVARES, 2005, p. 42-43).

Como dito, das esferas da sociedade, foi o Direito que mais se ressentiu do advento da pós-modernidade. Dentro dele, então, foi, de forma mais drástica, a jurisdição constitucional atingida, que, pela relevância de suas decisões judiciais, muitas vezes, oferece limitações às decisões políticas e, por isso, necessita de um maior grau de legitimidade, o que se reflete nas bases institucionalizadoras do Estado Democrático Direito. Quer-se dizer que a jurisdição constitucional padece da mesma crise institucional pela qual passa o Estado Democrático de Direito, a Constituição e os limites de atuação do Poder.

O Estado Social, não obstante reconhecer uma série de direitos e implementar políticas públicas variadas, possui como traço distintivo das formas de Estado que o antecederam a preocupação com os direitos sociais, econômicos e culturais relacionados à igualdade, à dignidade da pessoa humana e à cidadania. Direitos estes antes ignorados passaram por diferentes caminhos 
a serem objeto de proteção. Além dos direitos individuais já consagrados, converteram-se em tarefas do Estado também a educação, saúde, assistência social, previdência e acesso à justiça, bem como trabalho, lazer, segurança e moradia, resultantes da reflexão antiliberal e inspirada na defesa da igualdade, típica do século XX.

Diz-se Estado Democrático de Direito aquele que é regido por normas pré-fixadas (de Direito), onde a criação destas normas deve contar com a participação ativa da população (Democrático) e que, finalisticamente, vise construir uma forma de organização política que proporcione bem-estar à população, o chamado Welfare-State, atendendo, principalmente, às necessidades dos hipossuficientes sociais. Isto significa a necessária simbiose entre três elementos imprescindíveis à sociedade hodierna: regulamentação da sociedade pelo Direito, democracia participativa e concretização dos direitos fundamentais, sendo os dois primeiros os que garantem a fecundidade do terreno para o desenvolvimento deste último.

O Welfare-State surgiu nos países europeus devido à expansão do capitalismo após a Revolução Industrial e o movimento de um Estado Nacional visando a democracia, ou seja, deu-se com a superação do absolutismo e a emergência das democracias de massa. É uma transformação do próprio Estado a partir das suas estruturas, funções e legitimidade.

Importante aqui anotar a relevância da teoria de Keynes para a origem do Estado de bem estar. Esta teoria atribuiu ao Estado o poder regulador econômico da conjuntura, efetuando, além desse papel, outras medidas como a implementação de serviços sociais como forma de aumentar a demanda em momentos em que não seja suficiente para manter o pleno emprego. Contudo, a partir dos anos 1960 e 1970, este modelo de desenvolvimento keynesiano passou a dar sinais de esgotamento, caracterizado por estagnação, instabilidade financeira e queda de produtividade.

Nesta seara, o Welfare-State significou, sobretudo em países europeus que experimentaram padrões de políticas públicas mais universais, um novo arranjo econômico-político nas estruturas jurídicas dos Estados.

Há que se ressaltar, por oportuno, a tendência de um novo esquema de proteção social denominado de Welfare Mix, que incentiva a introdução das organizações empresariais e do terceiro setor na área das políticas sociais. São o que se pode chamar de as novas configurações do Estado, baseadas nos processos de ajuste estrutural de cunho neoliberal ocorridos desde as três últimas décadas do século XX. 
Sob ângulo oposto, encontra-se o Estado Liberal cuja Constituição vislumbra uma intervenção mínima dos órgãos estatais na sociedade, sem compromisso substancial do Estado na concretização de direitos ou no estímulo à formação de uma democracia participativa, o bem comum subordina-se aos cânones dos interesses individuais. Assim foi que o fechamento ao afloramento dos direitos fundamentais contribuiu decisivamente para a derrocada deste modelo de Estado. Defendem os liberais que na colisão de direito fundamental com a autonomia da livre iniciativa, prevalece esta.

De forma contrária, pois, atua o Estado Democrático de Direito, forma de Estado que mais se aproximou, adequou e permitiu o desenvolvimento dos direitos fundamentais, visando garantir através de prestações fornecidas por seus entes a concretização das demandas essenciais à população.

Porém, inobstante representar um avanço face ao Estado Liberal, não ficou de fora da crise pós-moderna, vez que foi afetado em sua essência, desestruturando-se, abrindo espaço, assim, para o afloramento do hoje denominado Estado Constitucional Democrático de Direito.

Segundo o Professor Danilo Zolo (2005), as motivações da crise do Estado Democrático Social de Direito podem ser creditadas a duas causas: o fenômeno da complexidade social nas sociedades de economia avançada e o processo de integração em escala global, a globalização.

Acredita Zolo que todas as crises que assaltam a organização política atual podem ser resumidas em uma crise do Estado de Direito, atingindo de modo frontal a sua estrutura de garantia dos direitos fundamentais. Sabese, porém, que jamais uma crise desta natureza complexa pode resumir-se a duas causas, devendo-se reconhecer a existência de diversos outros fatores que estimulam este processo e contribuem para a perda do paradigma normativo dos entes que compõem a organização política.

Importa destacar, nesta esteira, a inflação legislativa como motivo jurídico da crise. Para se adequar à constante evolução social, o ordenamento jurídico necessita produzir novos dispositivos para que estes possam acompanhar os fatos sociais sem entrar em contradição com eles. Ocorre que essa constante mutação/criação de normas gera insegurança, antinomias, inconstitucionalidades.

Por outro lado, pela influência da concepção liberal de Estado, na esfera econômica há um fenômeno inverso da inflação legislativa: a deficiência na capacidade regulativa do Estado, o que contribui para o 
agravamento da crise. Ela se manifesta em dois sentidos: na ausência de eficácia de suas estruturas normativas, mormente as normas programáticas ou no impedimento de regulamentação legal de determinada seara fática. No primeiro sentido, há um enfraquecimento dos órgãos estatais que deixam de realizar as suas funções. No segundo, os órgãos estatais deixam de regulamentar determinadas searas em razão de uma proibição legal.

Outra grande agravadora da situação caótica no regime democrático é a ausência de participação dos cidadãos. Os assuntos da pauta política são cada vez mais complexos e debatidos mediante linguagem fechada ao grupo, de modo que a população fica excluída da possibilidade de compreender quaisquer discussões e, portanto, de posicionar-se. Restamlhes, apenas, os meios de comunicação como fonte de informação mais ou menos cognoscível. Em vão. Os meios de comunicação "acessíveis" aos cidadãos são detidos nas mãos dos poderosos grupos econômicos que contribuem mais para alienar a cidadania do que para informá-la. Assim, o jogo político fica restrito à concorrência das elites políticas que se esganam pelo poder, figurando a população como mera expectadora.

Com este posicionamento concorda Marcelo Neves, ao acrescentar que

[...] o Estado Democrático de Direito confronta-se internamente com o problema de uma crescente indiferença da população não apenas em relação aos conteúdos das decisões políticas e normas jurídicas, mas também com respeito ao significado de seus procedimentos básicos.

E continua:

[...] quando a indiferença amplia-se excessivamente, atingindo, sobretudo, o significado dos procedimentos, pode-se falar de uma apatia pública que obstaculiza a capacidade aprendizado e o desenvolvimento do Estado de Direito (NEVES, 2008, p. 225).

Walber de Moura Agra (2005) entende que a crise do regime democrático é caracterizada tanto por uma ausência de legitimação popular, como por uma impossibilidade de resposta às demandas da sociedade. Compreende-a como uma falência funcional do regime democrático em atender as mais variadas demandas sociais, haja vista que, em uma sociedade estruturada por uma composição multipolar e fragmentada, configura-se 
impossível realizar uma estrutura normativa que possa atender a todos os segmentos. Acrescenta, ademais, que a crise do regime democrático significa ainda a alienação de grande parte da população das decisões políticas, insinuando que as decisões tomadas pelo governo sejam para atender aos interesses de determinados setores sociais em detrimento da maioria dos cidadãos.

\section{CONSIDERAÇÕES FINAIS}

Face o exposto, há que se dizer que os textos constitucionais, por si só, não servem mais como leis fundamentais estruturantes de uma realidade social, visto que em sua grande maioria são o que Karl Loewenstein denomina de Constituição Semântica, ou seja, aquelas que têm finalidade de servir como instrumento para a perpetuação das classes dominantes no poder. Exercendo o papel que o professor Pinto Ferreira (1996) denomina de "Ilusão Constitucional".

Neste sentido, a lição do Professor Marcelo Neves ao dizer que “[...] a política simbólica serve antes à harmonia social, reduzindo tensões e, portanto, desempenhando primariamente uma função aquietadora do público" (NEVES, 2007, p. 24). Conforme posicionamento desse jurista, pode-se dizer que a marca distintiva dessa conjectura de simbolismos legiferantes é a produção de textos cuja referência manifesta à realidade é normativojurídica, mas que serve, primária e hipertroficamente, às finalidades políticas de caráter não especificamente normativo-jurídico, definindo-a como aquela em que há o predomínio ou hipertrofia da função simbólica, essencialmente político ideológica, em detrimento da função jurídico-instrumental, de caráter normativo-jurídico.

A crise constitucional e do Estado Democrático de Direito, diante desses pressupostos fáticos e jurídicos, resvala na ausência de perspectivas éticas, políticas e sociais, fazendo com que a Constituição deixe de ser parâmetro normativo e perca eficácia, o que Konrad Hesse denominou de força normativa, de onde decorre a desordem nas relações sociais, fragmentando a concepção de Poder Constituinte e sua supremacia no ordenamento jurídico.

As normas programáticas desenvolvem a forma mais contundente da crise constitucional, pois que ocupam o ápice da pirâmide jurídica, mas 
apenas de forma retórica. Não conseguem ter eficácia positiva ou negativa, nem conseguem concretizar o conteúdo previsto no seu texto.

Aqui, pois, insurge o magistério do Prof. Artur Cortez Bonifácio (2008, p. 285), para quem é necessário assegurar a universalização do acesso à justiça, que pode ser compreendida nos aspectos político (pois a facilitação do recurso, às vias jurisdicionais é uma decisão de poder), social (inclusão social) e jurídico (observância das leis de processo e dos meios jurídicos disponíveis na Constituição). Nesta ocasião, pois, ter-se-á a transformação do acesso formal à justiça em acesso efetivo, em prol dos direito sociais básicos.

Pode-se inferir, neste ponto, que, essencialmente, a crise constitucional reside na ausência de eficácia destes dispositivos, dos mais elementares dispositivos da Constituição, decorrendo este desfalecimento do próprio enfraquecimento do Estado como responsável pela implementação das políticas públicas. Adicione-se, ademais, a globalização, que subordina em escala maior ou menor a Constituição aos seus ditames, de modo que em importantes momentos esta deve se adequar às normas de órgãos estranhos à soberania estatal, aprofundando a crise e atingindo a jurisdição constitucional que entra também em crise como um reflexo do caos no direito legislado, semelhante ao "efeito dominó".

Com efeito, no que pertine à crise da jurisdição constitucional, há que se dizer que esta se torna imprescindível para a criação de um Estado Democrático de Direito no momento que os entes estatais têm que atuar de forma incisiva na sociedade, para realizar as prestações insculpidas na Constituição e desenvolver os direitos da democracia participativa. Não se limita mais a resguardar a tutela individual dos cidadãos, preocupando-se de forma redobrada com a concretização do Welfare-State e a consequente criação de uma rede de proteção aos hipossuficientes e, de forma mais ampla, em garantir a concretização dos direitos fundamentais, numa nítida ligação. Retrato do nascimento de um novo modelo de Estado, o Estado Constitucional Democrático de Direito.

\section{REFERÊNCIAS}

\section{AGRA, Walber de Moura. A reconstrução da legitimidade do Supremo}

Tribunal Federal: densificação da jurisdição constitucional brasileira. Rio de Janeiro: Forense, 2005. 
BARROSO, Luís Roberto. Neoconstitucionalismo e constitucionalização do Direito. O triunfo tardio do Direito

Constitucional no Brasil. Jus Navigandi, Teresina, ano 9, n. 851, 1 nov. 2005. Disponível em: $<$ http://jus2.uol.com.br/doutrina/texto.asp?id=7547>. Acesso em: 16 nov. 2012.

BONIFÁCIO, Artur Cortez. O Direito Constitucional Internacional e a Proteção dos Direitos Fundamentais. São Paulo: Método, 2008. Coleção Professor Gilmar Mendes

CANOTILHO, J. J. Gomes. Direito Constitucional. Coimbra: Almedina, 1991.

DURKHEIM, Émile. "O que é fato social?", "Solidariedade mecânica", "Solidariedade orgânica" e "Preponderância progressiva da solidariedade orgânica". In: Durkheim. Org. J. A. Rodrigues. Coleção Grandes Cientistas Sociais. São Paulo: Ática, 2005.

FERREIRA, Pinto. Curso de Direito Constitucional. 8. ed. São Paulo: Saraiva, 1996.

GOSTA, Esping-Andersen. O Futuro do Welfare State na nova ordem mundial. Revista Lua Nova No. 35, São Paulo, CEDEC, 1995.

HABERMAS, Jurgen. Direito e Democracia - entre facticidade e validade I. Tradução de Flávio Beno Siebeneichler. Rio de Janeiro: Tempo brasileiro, 2003.

HESSE, Konrad. A força normativa da constituição. Tradução Gilmar Ferreira Mendes. Porto Alegre: Sérgio Antonio Fabris, 1991.

HELLER, Herman. Teoria do Estado. São Paulo: Mestre Jou, 1968.

KELSEN, Hans. Teoria Pura do Direito. Trad. João Baptista Machado. 6. ed. São Paulo: Martins Fontes, 1998.

LASSALE, Ferdinand. A essência da Constituição. 6. ed. Rio de Janeiro: Lumen Juris, 2001. 
LASSALE, Ferdinand. O que é uma Constituição. Trad. Hiltomar Martins Oliveira. Belo Horizonte: Líder, 2002.

LOPES, Francisco Cleidson Tavares. Do constitucionalismo ao neoconstitucionalismo: a busca pela efetividade do princípio da dignidade da pessoa humana. Disponível em: www.cesrei.com.br/ojs/ index.php/orbis/article/view/23/18. Acesso em 30 de dez. 2012.

LUHMANN, Niklas. Introducción a la teoría de sistemas. Guadalajara: Barcelona: Anthropos, 1996.

LUHMANN, Niklas. Sociedade y sistema: la ambición de la teoría. Tradução de Santiago López Petil y Dorothee Schmitz. Barcelona: Paidós, 1997.

NEVES, Marcelo. Entre Têmis e Leviatã: uma relação difícil. $1^{\text {a }}$ ed. São Paulo: Martins Fontes, 2008. 2009.

, Marcelo. Transconstitucionalismo. São Paulo: Martins Fontes, , Marcelo. A Constitucionalização Simbólica. São Paulo: Martins Fontes, 2007.

SCHMITT, Carl. O Conceito do Político. Tradução de Álvaro Valls. Petrópolis: Vozes, 1992.

SMEND, Rudolf. Constituzione e diritto constituzionale. Trad. F. Fiore e J. Luther. Milano: Giuffre, 1988.

TAVARES, André Ramos. Teoria da Justiça Constitucional. São Paulo: Saraiva, 2005

ZAGREBELSKY, Gustavo. Introduzione. In: SMEND, Rudolf.

Costituzione e diritto costituzionale. Trad. F. Fiore e J. Luther. Milano: Giuffrè, 1988. 
ZOLO, Danilo; COSTA, Pietro (orgs). O Estado de Direito. História, Teoria, Crítica. São Paulo: Martins Fontes, 2006.

Artigo recebido em 01/10/13 e aprovado para publicação em $05 / 11 / 13$

Como citar: PEREIRA, Erick Wilson; SILVA, Marília Ferreira. Breve cotejo entre as teorias dos sistemas e do discurso e a "sombra" da crise do Estado Democrático de Direito. Scientia Iuris, Londrina, v.17, n.2, p.167-192, dez.2013. DOI: $10.5433 / 2178-8189.2013 \mathrm{v} 17 \mathrm{n} 2 \mathrm{p} 167$. 